
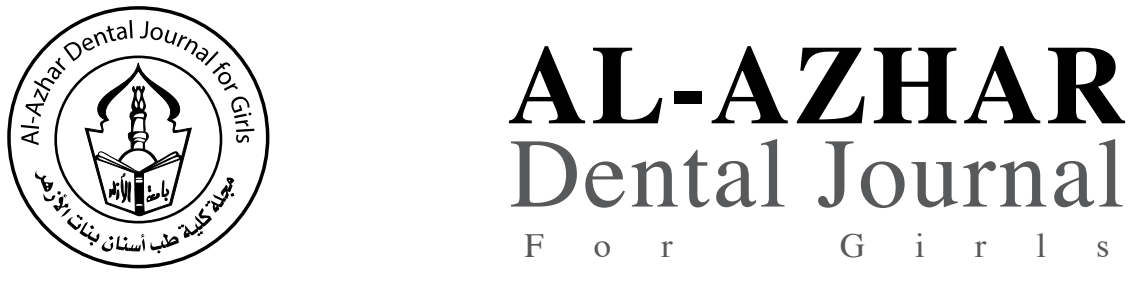

The Official Publication of The Faculty of Dental Medicine For Girls, Al-Azhar University Cairo, Egypt.

ADJ-for Grils, Vol. 4, No. 4, October (2017) — PP. 359:369

\title{
In Vitro Study Compared The Shear Bond Strength of HEMA-free and HEMA-containing Bonding Agents To Different Dentin Surface Treatments
}

\author{
Nady I. Mohammed ${ }^{(1)}$, Wakwak MA ${ }^{(2)}$ and Hamed I. Al-Kady ${ }^{(3)}$
}

Codex : 42/1710

drnadyhasanin75@gamil.com

\section{KEYWORDS}

HEMA-free, HEMA-containing

bonding agents and dentin

surface treatments

\section{ABSTRACT}

This research was designed to investigate the effect of two dentin surface treatments on the shear bond strength of HEMA-free and HEMA containing bonding agent. A total of 90 freshly extracted, sound human molars, free from caries, extracted for pathological reasons was used in this study. The molars were randomly divided into two main equal groups (45 teeth each) according to the type of adhesive system; Group (A1) used HEMA-free adhesive (G-bond). Group (A2) used HEMA containing adhesive (One-up Bond F Plus). Each group was further subdivided into 3 equal subgroups (15teeth each) according to the type of dentin surface treatments applied as follows: Subgroup (I) used the bonding agent only without surface treatment as a control $[\mathrm{AB}]$, Subgroup (II) used 10\% Sodium hypochlorite followed by the bonding agent [AB1], Subgroup (III) used 10\% Sodium hypochlorite then $10 \%$ Sodium ascorbate followed by the bonding agent [AB2]. Each subgroup was further divided into three groups of (5 teeth each) according to the storage times; 24 hours, three months, and six months. A Flat dentin surface was prepared, different surface treatments and adhesive systems were applied then Composite was bonded to the treated surfaces according to the manufacturer's instructions and the shear bond strength testing was done using universal testing machine. The recorded values were tabulated and statistically analysed. The result of this study revealed that; the highest mean shear bond strength $(18.39+/-2 \mathrm{MPa})$ was recorded for those dentin specimens bonded to composite resin with HEMA-containing adhesive (One-up Bond F Plus) without surface treatment after 1 day storage time. While the lowest mean shear bond strength $(10.7+/-1.6 \mathrm{MPa})$ was recorded for those dentin specimens bonded to composite resin with HEMA-free adhesive (G-bond) with sodium hypochlorite only after 6 months storage time. The results of this study revealed that 1 - Sodium hypochlorite only has a significant adverse effect on the shear bond strength of both adhesives. 2- sodium hypochlorite followed by sodium ascorbate can render the adverse effect of sodium hypochlorite only on the shear bond strength of both adhesives.3- HEMA-containing adhesive (One-up Bond F Plus) without surface treatment showed better shear bond strength than HEMA-free adhesive (G-bond). 4-Storage in water for long periods has a highly significant adverse effect on the bond strength especially of HEMA-containing adhesive.

1. Assistant Professor in Operative Department, Faculty of Dental Medicine, Al-Azhar University (Cairo- Boys) 


\section{INTRODUCTION}

The primary aim of dental adhesives is to provide retention to the resin composite fillings. In addition to withstanding mechanical forces, and in particular shrinkage stress from the resin composite, a good adhesive also should be able to prevent leakage along the restoration's margins ${ }^{(1)}$. Clinically, failure of restoration occurs more often due to inadequate sealing, with subsequent discoloration of the cavity margins, than loss of retention. ${ }^{(2)}$ Recently, adhesive systems have been introduced for easier and faster bonding procedures to tooth substrates using only a single application step, which are call 'one-step self-etch' adhesives. These adhesives combine the three functions of a three-step procedure (etching, priming and bonding). ${ }^{(3)}$

The presence of the hydrophilic monomer; 2-hydroxyethyl methacrylate (HEMA), is advisable for maintaining resin monomers in one solution and preventing phase-separation ${ }^{(4)}$. However, HEMA has been recently recognized as promoting waterforming unstable soft hydrogels prone to hydrolytic degradation. Moreover, omission of HEMA from adhesive blends has been considered advantageous in removing water, separating it from the other components upon solvent evaporation ${ }^{(5)}$. Therefore HEMA-free one-step adhesives might be different in dentine bonding durability from HEMA-containing one-step adhesives. ${ }^{(6)}$ Some researchers stated that the elimination of exposed collagen using sodium hypochlorite not only reduces technique sensitivity, but also allows the achievement of a more porous surface, which would be responsible for adhesive interfaces with similar bond strength values to those obtained in enamel after etching with phosphoric acid. $^{(7)}$

Compromised bond strengths were observed for some single-bottle adhesives when dentin was treated with sodium hypochlorite due to the oxidizing instead of the deproteinizing effect of sodium hypochlorite. The compromised bond strength could be reversed by the application of a reducing agent such as sodium ascorbate to the oxidized dentin; this will be the main hypothesis of the current study. ${ }^{\left({ }^{8}\right)}$

\section{MATERIALS AND METHODS}

\section{Materials used:}

Two types of self-etch adhesive systems ,two types of dentin surface treatments, and Hybrid composite resin were used in this study are listed in table (1)

\section{Methods:}

\section{Teeth selection and Grouping;}

A total of 90 freshly extracted, sound human molars, free from caries, extracted for pathological reasons were used in this study. The molars were randomly divided into two main equal groups (45 teeth each) according to the type of adhesive system; Group (A1) used G-bond adhesive. Group (A2) used One-up Bond F Plus adhesive. Each group was further subdivided into 3 equal subgroups (15teeth each) according to the type of dentin surface treatments applied as follows: Subgroup (I) used the bonding agent only without surface treatment as a control [AB], Subgroup (II) used 10\% Sodium hypochlorite followed by the bonding agent [AB1], Subgroup (III) used 10\% Sodium hypochlorite then $10 \%$ Sodium ascorbate followed by the bonding agent $[\mathrm{AB} 2]$. Each subgroup was further divided into three groups of (5 teeth each) according to the storage times; 24 hours, three months, and six months.

\section{2- Preparation of specimens:}

\section{$A$ - Fabrications of the molds:}

A specially fabricated stainless steel mold (opened from the top and the bottom) with dimensions; $23 \times 14 \times 19 \mathrm{~mm}$ in height, width and length respectively, was fabricate to create a standardized acrylic blocks in which the teeth were embedded vertically in it. The mold filled with selfcure acrylic resin leaving about $2 \mathrm{~mm}$ of the crown 
Table (1) Brand name, Composition, and Manufacture of the material used:

\begin{tabular}{|c|c|c|c|}
\hline Material s & Brand name & Composition & Manufacturer\&Batch no. \\
\hline $\begin{array}{l}\text { 1- One step self etch } \\
\text { adhesive system;( } \\
\text { HEMA-free ) }\end{array}$ & G -bond & $\begin{array}{l}\text { 4-META*, phosphoricester monomer, } \\
\text { UDMA***, TEGDMA }^{\#} \text {, acetone, water, stabi- } \\
\text { lizer, silica filler, water, photo-initiator }\end{array}$ & $\begin{array}{l}\text { GC, Tokyo, } \\
\text { Japan } 002277\end{array}$ \\
\hline $\begin{array}{l}\text { 2- One step self etch } \\
\text { adhesive system; } \\
\text { (HEMA-contain-ing) }\end{array}$ & $\begin{array}{l}\text { One-up Bond F } \\
\text { Plus }\end{array}$ & $\begin{array}{l}\text { Bonding agent A: MAC }{ }^{\star}-10, \text { photo-initiator, } \\
\text { methacryloylalkyl acid phosphate, multifunc- } \\
\text { tional methacrylic monomer. } \\
\text { Bonding agent B: MMA } \text { A }^{* * * *}, \text { HEMA }^{\& * *}, \text { water, } \\
\text { F-deliverable micro-filler (fluoroaluminosilicate } \\
\text { glass), photo-initiator }\end{array}$ & $\begin{array}{l}\text { Tokuyama } \\
\text { Dental Corporation, } \\
\text { Tokyo, Japan } \\
45447113\end{array}$ \\
\hline $\begin{array}{l}\text { 3- Dentin surface } \\
\text { treatment }\end{array}$ & $\begin{array}{l}10 \% \text { Sodium } \\
\text { Hypochlorite } \\
10 \% \text { Sodium } \\
\text { ascorbate }\end{array}$ & $\begin{array}{l}\text { Sodium Chloride } \\
\text { Water } \\
\text { Energy } \\
\text { Sodium hydroxide }\left(\mathrm{Na}_{2} \mathrm{OH}\right) \\
\text { Ascorbic acid }\end{array}$ & $\begin{array}{l}\text { Gomhouria } \\
\text { pharmaceutical company } \\
26406 \\
\text { Gomhouria pharmaceutical } \\
\text { company } \\
26407\end{array}$ \\
\hline $\begin{array}{l}\text { 4-Hybrid resin } \\
\text { Composite }\end{array}$ & Filtek Z250 & $\begin{array}{l}\text { Filler: zirconia/silica }(60 \mathrm{vol} \%) \text { Its matrix is } \\
\text { composed of Bis-GMA }{ }^{\& \#}, \text { UDMA, and Bis- } \\
\text { EMA }^{\& \# *} \text {. The filler is zirconia /silica with } \\
\text { particle size range of } 0.01 \mu \mathrm{m} \text { to } 3.5 \mu \mathrm{m} \text {. The } \\
\text { inorganic filler loading is about } 60 \% \text { vols. }\end{array}$ & $\begin{array}{l}\text { 3M ESPE dental products St. } \\
\text { Paul, MN } \\
\text { U.S.A55144 } \\
\text {. }\end{array}$ \\
\hline
\end{tabular}

4-META4- = "methacryloyloxyethyl trimellitic acid Bis GMA ${ }^{\& \#}=$ Bisphenol glycidyl methacrylate.

$U D M A^{* *}=$ Urethane dimethacrylat $M A C-10^{\star}=11$-methacryloyloxy-1, 10-undecanedicarboxylic acid .

$T E G D M A^{\#}=$ Tri-ethelene glyccidyl dimethacrylate. Bis- EMA ${ }^{\& \# *}=$ Ethoxylated bisphenol A glycol dimethacrylate .

$M M A^{\# * *}=$ Methyl methacrylate. HEMA ${ }^{\star 2} 2={ }^{* *}$ hydroxy ethyle methacrylate

above the surface. The base of the mold resting on a glass slab to obtain a flat smooth surface base. Another special fabricated copper mold, with central hole of $3 \mathrm{~mm}$ internal diameters and $3 \mathrm{~mm}$ height was designed for the purposes of production standardize size of specimen's restorative materials $(3 \mathrm{X} 3 \mathrm{~mm}$ in diameter). This mold has two splitted parts that could be guided to fit into each other with surrounding copper ring. In addition, special fabricated stainless steel holder was designed in Figure (1). This holder consists of two parts; the upper part and the lower part. The upper part together with the lower part allows for adaptation and fixation of the mold ring to the flattened dentin surface during application of the restorative material.

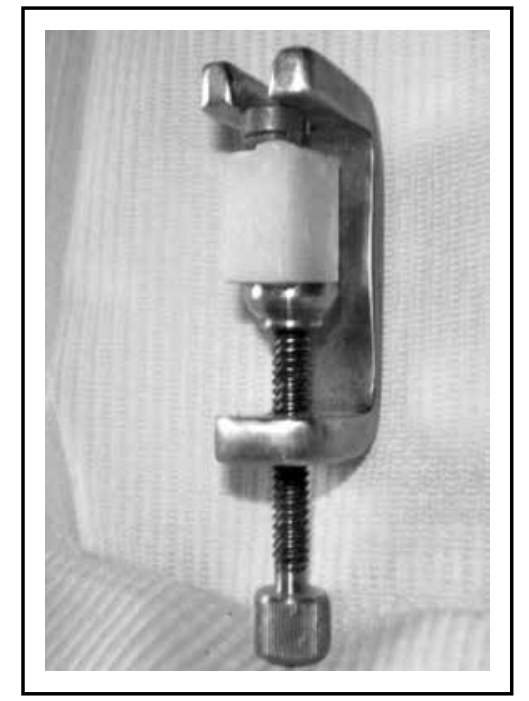

Fig. (1) Holder with block Upper part has U shape space Specimens The lower part has screw 
B-Preparation of the dentin surface and application of the restorative material:

The flat dentin surface were produce using a special abrasive stone under coolant to create a depth cut grooves with full depth of the stone $(2 \mathrm{~mm})$. Then united together to remove the projected occlusal surface of the tooth in the acrylic block to create a flat dentin surface, just passing the dentino-enamel junction. This depth was remarked on all occlusal surface of the crown. A graduated periodontal probe was used to confirm the depth.

\section{Application of the restorative material:}

Each restorative material was applied according to manufacturer instructions; The first subgroup; the adhesive applied as the following; the acrylic block with the dentin specimen inside was placed into the specially designed holder with the split brass ring placed in the central portion of the dentin specimen. Dentin dry by air blowing. The bottle of bonding agent was shaking well before use. G-bond ;One drop of G-bond was placed into the mixing well. The bonding agent was applied to dentin surface by the disposable applicator tip and leave undisturbed for10 second. The bonding agent was dry thoroughly for 5 second, bonding agent was light cured for 20 second. One-up Bond F Plus; One drop of bonding agent $\mathrm{A}$ and bonding agent $\mathrm{B}$ was placed into the mixing well and mix well until the mixed bonding agent turns completely to pink color. The mixed bonding agent was applied to dentin surface by the disposable applicator tip. The mixed bonding agent was kept rubbing on the surface for at least 10 second bonding agent was light cured for 10 second. The second subgroup of specimens was treated with $10 \%$ Sodium hypochlorite solution for 60 second, then water rinsed for 30 second, and blotted dry with tissue paper followed by bond was applied as described before. The third subgroup of specimens were treated with $10 \%$ Sodium hypochlorite $(\mathrm{NaOCl})$ solution 60 second, then water rinsed for 30 second and blotted dry with tissue paper, followed by $10 \%$ Sodium ascorbate was ap- plied for 60 second, followed by water rinsing for 15 second and blotted dry with tissue paper, then applying bond as described before.

Application of composite resin:After application of dentin surface treatments and adhesive systems, the composite resin (Filtek Z250) was applied according to the manufacturer instruction in two increments (each increment about $1.5 \mathrm{~mm}$ thickness) and packed in the ring using a Teflon coated instruments. Each increment was light cured for $40 \mathrm{sec}-$ onds with a light-curing unite . Acelloid matrix was applied on top of composite resin and thin glass slid was used to compress the restorative material in the last increment before curing to attained high smooth surface. Finally, after curing, the acrylic blocks were ejected from the stainless steel holder and the split brass ring was removed and addition cure for 40 seconds was done to the lateral side of specimens.

\section{2- Storage of specimens:}

The specimens were stored in distilled water at $37^{\circ} \mathrm{C}$ in an incubator with $100 \%$ humidity at different storage time (24 hours, one week, one month, and three months) until shear bond strength testing was performed.

\section{3-Testing procedure:}

Shear bond strength testing was performed on the specimen using a computerized testing machine (Lloyed testing England) at speed of $0.5 \mathrm{~mm} /$ min. Each specimen was fixed to a holder device placed on the lower compartment of the machine to prevent movement of the specimen during testing. A specially constructed blunt edge metal attachment of $3 \mathrm{~mm}$ in thickness, $70 \mathrm{~mm}$ in length, and $10 \mathrm{~mm}$ in width was attached to the upper component of the machine. The attachment has a hole that matched the size of specimen $(3 \mathrm{~mm}$ in diameter and $3 \mathrm{~mm}$ in thickness). The attachment was adjusted so as to get a shearing force using a crosshead speed of $0.5 \mathrm{~mm} / \mathrm{min}$ until failure occurred. The shear bond strength in MPa was calculated for all specimens tested from the following equation: 
$S B=L / A$

$S B=$ shear bond strength in $\mathrm{MPa}$

$L=$ breaking load in Newton

$A=$ area of restoration / dentin interface in $\mathrm{mm}^{2}$

Area $=I I r^{2}$ in $\mathrm{mm}^{2} \quad I I=3.14$ or 22/7 $r=$ diameter $/$ $2=6 \mathrm{~mm} / 2=3 \mathrm{~mm}$.

Then the data were presented as mean and standard deviation (SD) values and doing statistical analysis using Turkey's test showing the result.

\section{RESULTS}

Comparison between the two bonding agents The mean shear bond strength (MPa) and standard deviation (SD) between the dentin specimens bonded with two different bonding agents; One-up Bond F plus and G-Bond to direct restorative material; Filtek Z250, showing in figure (2) at different storage times; 24 hours, three months, and six months.

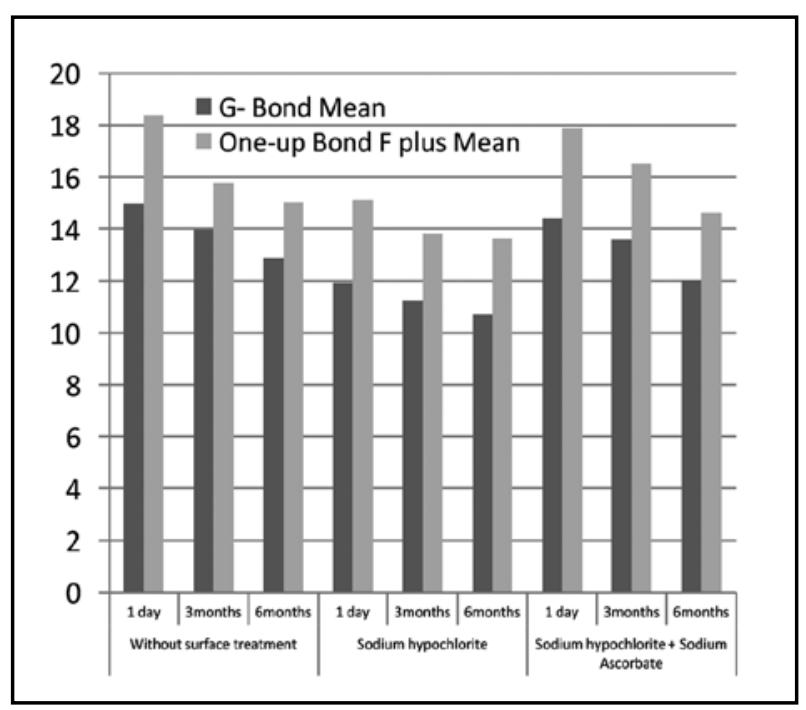

Fig. (2) Bar chart showing Comparison between the two bonding agents.

A- G-Bond: Without surface treatment, the highest mean shear bond strength $(14.99+/-1.4$ $\mathrm{MPa})$ was recorded for those dentin specimens bonded to composite resin after 1 day storage time while the lowest mean shear bond strength $(12.88+/-1.8 \mathrm{MPa})$ was recorded after 3 months storage time. With Sodium hypochlorite, the highest mean shear bond strength $(11.92+/$ $1.8 \mathrm{MPa})$ was recorded for those dentin specimens bonded to composite resin after 1 day storage time while the lowest mean shear bond strength $(10.7+/-1.6 \mathrm{MPa})$ was recorded after 3 months storage time. With Sodium hypochlorite + Sodium Ascorbate, the highest mean shear bond strength (14.4 +/- 1.4 MPa) was recorded for those dentin specimens bonded to composite resin after 1 day storage time while the lowest mean shear bond strength $(12+/-1.7 \mathrm{MPa})$ was recorded after 3 months storage time.

B- One-up Bond F plus: Without surface treatment, the highest mean shear bond strength $(18.39+/-2 \mathrm{MPa})$ was recorded for those dentin specimens bonded to composite resin after 1 day storage time while the lowest mean shear bond strength $(15.03+/-1.4 \mathrm{MPa})$ was recorded after 3 months storage time. With Sodium hypochlorite, the highest mean shear bond strength $(15.12+/-1.9 \mathrm{MPa})$ was recorded for those dentin specimens bonded to composite resin after 1 day storage time while the lowest mean shear bond strength $(13.63+/-0.9 \mathrm{MPa})$ was recorded after 3 months storage time. With Sodium hypochlorite + Sodium Ascorbate, the highest mean shear bond strength $(17.86+/-2.3$ $\mathrm{MPa})$ was recorded for those dentin specimens bonded to composite resin after 1 day storage time while the lowest mean shear bond strength (14.64 +/- $2 \mathrm{MPa})$ was recorded after 3 months storage time .

\section{II- Comparison between the storage times}

The mean shear bond strength (MPa) and standard deviation (SD) between the dentin specimens treated with two different surface treatments; Sodium ascorbate and Sodium hypochlorite, bonded with two different bonding agents; One-up Bond F plus and G-Bond to direct restorative material; Filtek Z250, showing in figure. (3) at different storage times; 24 hours, three months, and six months. 


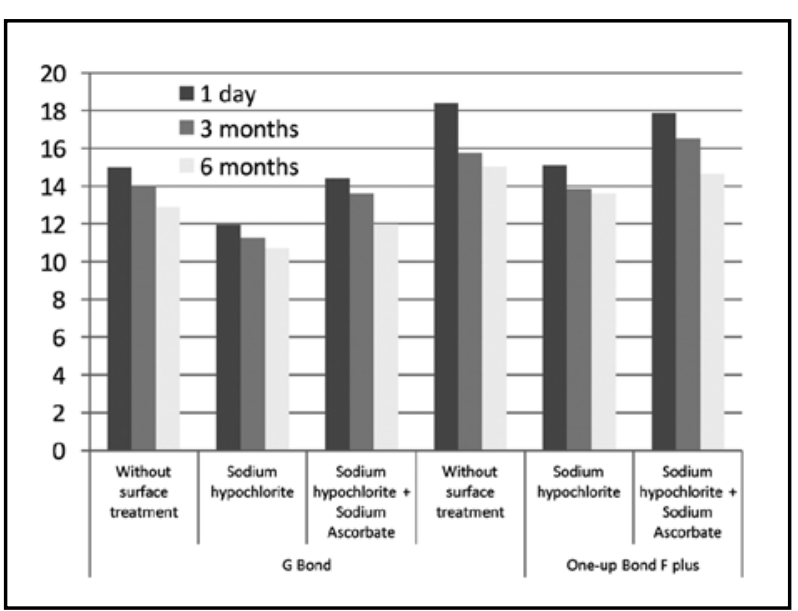

Fig. (3) Bar chart showing the mean shear bond (MPa) at different storage times

A- After 1 day; The highest mean shear bond strength $(18.39+/-2 \mathrm{MPa})$ was recorded for those dentin specimens bonded to composite resin with One-up Bond F plus without surface treatment while the lowest mean shear bond strength $(11.92+/-1.8 \mathrm{MPa})$ was recorded for those dentin specimens bonded to composite resin with G-Bond after Sodium hypochlorite.

B- After 3 months; The highest mean shear bond strength $(15.75+/-1.8 \mathrm{MPa})$ was recorded for those dentin specimens bonded to composite resin with One-up Bond F plus without surface treatment while the lowest mean shear bond strength $(11.26+/-1.8 \mathrm{MPa})$ was recorded for those dentin specimens bonded to composite resin with G-Bond after Sodium hypochlorite.

C- After 6 months; The highest mean shear bond strength $(15.03+/-1.4 \mathrm{MPa})$ was recorded for those dentin specimens bonded to composite resin with One-up Bond F plus without surface treatment while the lowest mean shear bond strength $(10.7+/-1.6 \mathrm{MPa})$ was recorded for those dentin specimens bonded to composite resin with G-Bond after Sodium hypochlorite.

\section{DISCUSSION}

The durability of bonds between resins and tooth substrates is of significant importance for the clinical longevity of adhesive restorations. ${ }^{(8)}$.

\section{Effect of HEMA on the shear bond strength to dentin}

The results of this study revealed that, HEMAcontaining provided highly bond strengths than HEMA-free adhesives. This may be related to the presence of the hydrophilic monomer; 2-hydroxyethyl methacrylate (HEMA) is advisable for maintaining resin monomers in one solution and preventing phase-separation ${ }^{(9)}$, its hydrophilicity makes it an excellent adhesion-promoting monomer ${ }^{(10)}$. By enhancing wetting of dentin, HEMA significantly improves bond strengths ${ }^{(11)}$. Moreover HEMA has good biocompatibility, and able to evaporate from the adhesive solutions, though only in very small amounts $^{(12)}$. Another explanation for this result, HEMA acts as a wetting agent and helps monomers to diffuse into the relatively deeply $(3-5 \mathrm{~mm})$ exposed collagen network within a clinically manageable time, thereby improving bond strength ${ }^{(13)}$. With wet bonding techniques, the channels between the demineralized dentin collagen fibrils are filled with water, solvent, conditioner, and/or oral fluids $^{(14)}$. The only mechanism available for adhesive resin infiltration is diffusion of the resin into whatever fluid is in the spaces of the substrate and along the collagen fibers. Ideally, the solvent/HEMA combination conditions the collagen to remain expanded during adhesive infiltration. However, results from a recent study indicate that HEMA, which is a primary component in many single-bottle commercial dentin adhesives, can dramatically reduce the evaporation of water ${ }^{(15)}$. This in agreement with the results obtained by Van Landuyta et al $2007^{(16)}$, who concluded that: $10 \%$ of HEMA improved the bond strength of a one-step self-etch adhesive,also better wetting and infiltration properties of the adhesive.

This disagree with the results obtained by Carvalho $\mathrm{R}$ et al $2007^{(17)}$ concluded that: HEMAfree one-step adhesives are complex blends hydrophilic/hydrophobic ingredients, water and solvents, thereby improving bonding effectiveness. When added HEMA in higher concentrations, this benefi- 
cial effect of HEMA on the bond strength may be lost due to increased hydrophilicity, decreased removal of water and reduced co-polymerization. ${ }^{(18)}$

\section{II- Effect of dentin surface treatments on shear bond strength:}

Effect of sodium hypochlorite;The results of the current study revealed that sodium hypochlorite $(\mathrm{NaOCl})$ show lower shear bond strength of both HEMA-containing and HEMA-free adhesives. This may be related to the $\mathrm{NaOCl}$-treated surfaces seem to be free of loose collagen fibrils ${ }^{(19)}$. The absence of naked collagen fibrils suggests that the polymer formed by light curing of adhesives could be degraded over the testing period. Hydrophilic resins, such as those present in the current adhesives, are highly prone to absorb water ${ }^{(20)}$. Since all adhesives used in the present study contain significant amounts of hydrophilic monomers, water sorption over time can also be regarded as a contributor to the observed reduction in bond strengths. In addition, failure in removing all residual water entrapped in the deepest regions of demineralized and deproteineized dentin induces the formation of poorly polymerized polymer chains ${ }^{(21)}$ that would be weaker and less stable over time than those formed in water-free regions. Additionally, the presence of reactive residual free-radicals as a result of the oxidizing action of $\mathrm{NaOCl}$, may compete with the propagation vinyl free-radicals generated during light-activation of the adhesive, resulting in premature chain termination and incomplete polymerization ${ }^{(22)}$. Also oxygen released by sodium hypochlorite molecules is another factor that might justify the decreased bond strength values, as it may inhibit adhesive polymerization and hence compromise the mechanical performance of the obtained bonding interfaces ${ }^{(23)}$. This is confirmed with the results obtained by Uceda-Gonez et al $2007^{(24)}$, who concluded that: The use of $10 \% \mathrm{NaOCl}$ for $1 \mathrm{~min}$ after dentin demineralization did not improved the bond strength to dentin either immediately or after a 1-year period.
Another explanation for this result, this may be related to changes in the physical and chemical properties of dentin after application of sodium hypochlorite. Reductions in the elastic modulus and flexural strength of dentin were reported after irrigation of the root canals with 5\% sodium hypochlorite ${ }^{(25)}$. This is confirmed with the results obtained by Silva EM,et al in $2007^{(26)}$, who concluded that: Residual sodium hypochlorite within the porosities of mineralized dentin may result in incomplete resin polymerization, and hence compromised bond strength the use of sodium ascorbate, reverses this compromised bond strength. This finding disagree with Torres et al in 2004 ${ }^{(27)}$ who reported that, after the application of $10 \% \mathrm{NaOCl}$ on the acid-etched dentin, the removal of the collagen network resulted in an extremely rough surface, with greater opening of the dentinal tubule orifices and exposing of lateral branches which suggest an increase in the surface area ${ }^{(28,29)}$, this leads to an increase in the capillary effect, in addition to an increase in surface energy because of the removal of the collagen fibers, which result in an increase in the wettability ${ }^{(30)}$. The results of the current study are also in disagreement with Blunck et al in $1997^{(31)}$, who observed a significant increase in the percentage of excellent margins after treatment with sodium hypochlorite in comparison to the conventional technique. This controversy may by due to differences in the materials that used or differences in methodology.

Effect of Sodium ascorbate; The results of the current study revealed that sodium hypochlorite followed by sodium ascorbate show higher bond strengths than sodium hypochlorite only of both HEMA-containing and HEMA-free adhesive without significant difference between sodium hypochlorite followed by sodium ascorbate and the control group. This may be related to dental adhesives polymerize by a free radical polymerization mechanism that involves the generation of free radicals through light-activated redox initiators ${ }^{(32)}$, Sodium ascorbate allows free-radical polymerization of the adhesive resin to proceed without premature termination by restoring the altered redox potential of the 
oxidized bonding substrate thus reversing the compromised bonding ${ }^{(33)}$. Ascorbic acid and its salts are well-known antioxidants and are capable of reducing a variety of oxidative compounds, especially free radicals ${ }^{(34)}$. This in agreement with the results obtained by Kimyai S. et al. $2008^{(35)}$, who concluded that, Reduced bond strength to bleached dentin can be amended by the use of sodium ascorbate as an antioxidant. Another explanation for this result, this may be related to Oxygen released by sodium hypochlorite molecules is might justify the decreased bond strength values, as it may inhibit adhesive polymerization and hence compromise the mechanical performance of the obtained bonding interfaces ${ }^{(36)}$. Compromised bond strengths were observed for some single-bottle adhesives when dentin was treated with sodium hypochlorite due to the oxidizing instead of the deproteinizing effect of sodium hypochlorite. The compromised bond strength could be reversed by the application of a reducing agent such as sodium ascorbate to the oxidized dentin ${ }^{(37,38)}$. The use of the sodium ascorbate, instead of the ascorbic acid, is recommended to avoid the potential doubleetching effect of this mild acid on etched teeth ${ }^{(39)}$. This is confirmed with the results obtained by Yiu et al in $2002^{(40)}$, who concluded that: Residual sodium hypochlorite within the porosities of mineralized dentin may result in incomplete resin polymerization, and hence compromised bond strength the use of sodium ascorbate, reverses this compromised bond strength

\section{D) Effect of storage time on the shear bond strength}

The results of the current study revealed that with G- Bond, without surface treatment, there was no statistically significant difference between mean shear bond strength after 1 day, 3 months and 6 months. This may be related to both in uncured and cured state, HEMA will readily absorb water. Some researchers hypothesized that HEMAcontaining adhesives are more susceptible to water contamination, as the HEMA in the uncured adhesive may absorb water, which can lead to dilution of the monomers to the extent that polymerization is inhibited ${ }^{(41)}$. HEMA fixed in a polymer chain after polymerizing will still exhibit hydrophilic properties and will lead to water uptake with consequent swelling and discoloration ${ }^{(42)}$. Apart from the water uptake, this adversely influences the mechanical strength; high amounts of HEMA will result in flexible polymers with inferior qualities ${ }^{(43)}$. The shear bond strength values of One-up Bond F plus, without surface treatment lowering after 3 months as result from the effect of hydrolysis at the bonding interface through over enlarging of the nanoleakage pathway. However, this nanoleakage or nanometer sized spaces within the hybrid layer may result from incomplete resin infiltration into the deminerialized dentin leaving the collagen unenveloped by resin ,or it may result from poor polymerization of the adhesive resin and the existence of low molecular weight oligomers ${ }^{(4)}$. This nanoleakage pathway may allow fluid penetration along the interface which may result in hydrolytic breakdown of either the adhesive resin or collagen within the hybrid layer, there compromising stability of the resin-dentin bond ${ }^{(45)}$. Another explanation for drop the shear bond strength values of One-up Bond F plus, without surface treatment after 3 months as result from hydrolytic degradation of the resin and collagen fibers in the submicron spaces of the hybrid layer increase with increase exposure to water ${ }^{(46)}$. In fact, during long-term water storage, the resin absorbs significant amount of water and consequently swelling of the resin may result in the closure of any space between the bonding resin and dentin surface. Conversely, stresses my simultaneously be induced at the bonding resindentin interface, which may pull the collagen fibers into the hybrid layer and resin, leading to tearing along the bonded interface as the collagen fibers become weaker over time from hydrolysis ${ }^{(47)}$. The increase storage period allow increase water uptake, that lead to increased permeability and increase the hydrolytic degradation of the material ${ }^{(48)}$. The water sorption and degradation process causing rapid drop in the physical properties, loss of resin from the hybrid layer and consequently, drop in the adaptation after long term water storage ${ }^{(49)}$. This findings in 
agreement with Sano et al in $1999^{(50)}$, who suggested that the microleakage of the resinous materials increase after long-term water storage

This findings disagree with Mortier $\mathrm{E}$ et al in $2004^{(51)}$, who found that: after one year water storage, the dentin bond strength of all adhesive systems reduced significantly, except for One-Up Bond F They explain that, In this study the results indicated one year of water storage did not change the bond strength of One-Up Bond F self-etching adhesive. The $\mathrm{pH}$ of this material is 2.6 and it is close to the ideal acidity and etching aggressiveness. One-Up Bond $\mathrm{F}$ is a simplified bonding agent, and the bond strength stability may be related to low etching aggressiveness and low acid dissociation constants ${ }^{(52,53)}$. Moreover, each adhesive contains specific functional hydrophilic monomer that can determine its performance and hydrolytic stability over time. This controversy may by due to differences in methodology.

With Sodium hypochlorite only and Sodium hypochlorite + Sodium Ascorbate, showed statistically lowest mean shear bond strength after 3 months but not statistically significant difference with both One-up Bond F plus or G-bond. This may be related to the NaOCl-treated surfaces seem to be free of loose collagen fibrils ${ }^{(54)}$. The absence of naked collagen fibrils suggests that the polymer formed by light curing of adhesives could be degraded over the testing period. Hydrophilic resins, such as those present in the current adhesives, are highly prone to absorb water ${ }^{(55)}$. Since all adhesives used in the present study contain significant amounts of hydrophilic monomers, water sorption over time can also be regarded as a contributor to the observed reduction in bond strengths. In addition, failure in removing all residual water entrapped in the deepest regions of demineralized and demineralized and deproteineized dentin induces the formation of poorly polymerized polymer chains that would be weaker and less stable over time than those formed in water-free regions ${ }^{(56)}$.

\section{REFERENCES}

1. Van Landuyt, Snauwaert J, De Munck J, Poitevina A, Coutinhoa E, and Suzukic K. Systematic review of the chemical composition of contemporary dental adhesives. J. Biomat. 2007; 28:3757-65

2. Bachelar-S,GianniniK, and Bedran-R Bond strength and permeability of HEMA-free adhesives to biomodified dentin. Dent Mater -5641(14)X0011-4”2014;30:25-33

3. Van Meerbeek B, Vargas S, Yoshida Y, Peumans M, and Lambrechts P. Adhesive and cements to promote preservation dentistry. J. Operat Dent 2001; 26:119-24.

4. Miyazaki M, Sato M, and Onose H. Durability of enamel bond strength of simplified bonding systems. J. Operat Dent 2000; 25:75-80.

5. Ely C, Schneider LF, Ogliari FA, Schmitt CC, Correa IC,and Lima G. Polymerization kinetics and reactivity of alternative initiators systems for use in light-activated dental resins. Dent Mater. 2012;28:1199-206

6. Marília, Rodrigo, and Cesar H. Experimental self-etching HEMA-free adhesive systems: cytotoxicity and degree of conversion. J of Materials Science 2015;26:40-45

7. Jan W., Van D, and Pallesen U. Durability of a low shrinkage TEGDMA/HEMA-free resin composite system in Class II restorations. A6-year follow up. Dent Mater $2017 ; 10 ; 1-10$

8. Carvalho R.M, Mendonça J.S, Santiago S.L, Silveira R.R, Garcia $p$ and Tay FR. Effects of HEMA/Solvent combinations on bond strength to dentin. J. Dental Rese 2003; 82:597-601.

9. Van Landuyta K, De Munck J, Snauwaert J, Poitevin A, Peumans M, and Van Meerbeek B. Monomer-solvent phase separation in one-step self-etch adhesives. J. Dental Rese 2005; 84: 183-88

10. Reis A, Albuquerque M, Pegoraro M, Gracielle MB, Jose' Roberto OBC, and Alessandro D. Can the durability of one-step self-etch adhesives be improved by double application or by an extra layer of hydrophobic resin? J. Operat Dent 2008; 36: 309-15.

11. Cetinguc A, lmeza S, and Vural NF. HEMA diffusion from dentin bonding agents in young and old primary molars. J. Dent Mate 2005; 926: 8-13

12. Van D and Lindberg A. A 15-year randomized controlled study of a reduced shrinkage stress resin composite in Class II cavities. Dent Mater 2015;31:1150-8. 
13. Bakhsh TA, Sadr A, Shimada Y, Mandurah MM, and Hariri I. Concurrent evaluation of composite internal adaptation and bond strength in a class-I cavity. J Dent Mater 2013 ;41: 60-70.

14. Van D and Pallesen U. A randomized 10-year prospective follow up of Class II nano-hybrid and conventional hybrid resin composite restorations. J Adhes Dent 2014;16:585-92.

15. Emamieh S, Sadr A, Ghasemi A, Torabzadeh H, and Akhavanzanjani V. Effects of solvent drying time on mass change of three adhesives. J Conserv Dent 2013; 16: 418-422.

16. Van Landuyt, Snauwaert J, De Munck J, Peumansa M, Yasuhiro Y, and Suzukic K. Systematic review of the chemical composition of contemporary dental adhesives. J. Biomaterial. 2007; 28:3757-85

17. Carvalho R.M, Mendonça J.S, Sano S.L, Silveira R.R, Garcia $\mathrm{p}$ and Tay FR. Effects of HEMA/Solvent combinations on bond strength to dentin. J. Dental Research 2003; 82:597-601.

18. Malacarne J, Andrade E, Wang L, Goes MF,and Martins AL. Permeability of Dental Adhesives - A SEM Assessment. Eur J Dent2010;4: 429-439.

19. De Munck J, Banu Ermis R, Koshiro K, Van Meerbeek B, and Van Landuyta $\mathrm{K}$. NaOCl degradation of a HEMA-free all-in-one adhesive bonded to enamel and dentin following two air-blowing techniques. J. Dentistry 2007; 35: 74-84.

20. Castro A, Amaral CM, Ambrosano GB, and Pimenta LA. Effect of sodium hypochlorite gel on shear bond strength of one-bottle adhesive systems. J. Brazilian. Oral Science 2004; 3: 465-69.

21. Souza F.B. Vicente Silva CH, Palma Dibb RG, Delfino CS, and Souza Beatrice LC. Bonding performance of different adhesive systems to deproteinized dentin. J. Biomaterial 2005; 75:158-67.

22. Garcia p, and Silva EM. Nanoleakage phenomenon on deproteinized dentin. J. Applied Oral Science 2007; 15: 285-91

23. Ninoshka U, Carrllho AM, Logurcio AD, and Rodrigues LE. Effect of sodium hypochlorite on the bond strength of an adhesive system to superficial and deep dentin J. Applied Oral Science 2003; 11: 223-8.

24. Uceda-Gonez, Logurcio AD, Moura SK, Grande RM, Margareth OD, and Alessandra R. Long-term bond strength of adhesive systems applied to etched and deproteinized dentin. J. Applied Oral Science 2007; 15: 475-9

25. HYPERLINK “mailto:mturkun@bornova.ege.edu.tr" Turkun M and Kaya A D. Effect of $10 \%$ sodium ascorbate on the shear bond strength of composite resin to bleached bovine enamel. J. Oral Rehabilitation 2004; 31: 1184-91

26. Silva EM, Duarte P, Poskus LT, Barcellos AL, and Guimaes JA. Nanoleakage and microshear bond strength in deproteinized human dentin. J. Biomat 2007; 81:336-42.

27. Torres C, Araújo AM, and Mello C. examined the effects of dentin collagen removal on microleakage of bonded restorations. J. Adhesive Dentistry 2004; 5: 33-42.

28. Wakabayashi Y, Kondou Y, and Suzuki K. Effect of dissolution of collagen in adhesion to dentin. J. Int Prosthod 1994; 7: 302-6.

29. Pioch T, Kobaslija S, Schagen B, and Gotz H. Interfacial micromorphology and tensile bond strength of dentin bonding systems after $\mathrm{NaOCl}$ treatment. J. Adhesive Dentistry 1999; 2: 135-42.

30. Toledano M, Osorio R, Perdigao J, Rosales JI, Thompson JY, and Vilchez C. Effect of acid etching and collagen removal on dentin wettability and roughness. J. Biomedical Material Research 1999; 47: 198-203.

31. Blunck U, Speyer F, and Roulet JF. Effect of hypochlorite treatment of conditioned dentin on the marginal adaptation of composite resin restorations. J. Dental Research 1997; 76: $19-25$.

32. Vongphan N, Senawongse P, Somsiri W, and Harnirattisai C. Effects of sodium ascorbate on microtensile bond strength of total-etching adhesive system to $\mathrm{NaOCl}$ treated dentin. J. Dentistry 2005; 33: 689-95.

33. Bulut H, Turkun M, and Kaya AD. Tensile bond strength of brackets after antioxidant treatment on bleached teeth. J. European Orthodontic. 2005; 27: 466-71.

34. Lai SC, Mak YF, Cheung GS, Osorio R, Toledano M, and Carvalho RM. Reversal of compromised bonding to oxidized etched dentin. J. Dental Research 2001; 80:1919-24

35. Kimyai S and Valizadeh H. Comparison of the effect of hydrogel and a solution of sodium ascorbate on dentin composite bond strength after bleaching. J. Contemporary Dental Practice 2008; 9: 672-9.

36. Garcia R, Fernando M, and Giannini M. Effect of water storage on bond strength of self-etching adhesives to dentin. J. Contemporary Dental Practice 2007; 7: 46-53.

37. Lai SC, Mak YF, Cheung GS, Osorio R, Toledano M, and Carvalho RM. Reversal of compromised bonding to oxidized etched dentin. J. Dental Research 2001 80:1919-24 
38. Malacarne J, Ricardo M. Carvalho, and Mario F. Water sorption/solubility of dental adhesive resins. J. Dent Mater 2005; 11:20-8.

39. Perdigão J, Lopes M, Geraldeli S, Lopes GC, and García F. Effect of a sodium hypochlorite gel on dentin bonding. J. Dent Mater 2000; 16:311-23.

40. Yiu CK, Gracia-Goday F, Tay FR, Pashley D.H, Imazato S, King N.M and Lai S. Ananoleakage perspective on bonding to oxidized dentin. J. Dental Research 2002; 9: 628-32.

41. Monticelli F, Osorio R, Pisani-Proenca J, and Toledano M. Resistance to degradation of resin-dentine bonds using a onestep HEMA-free adhesive. J. Dentistry 2007; 35: 181-6.

42. Jacobsen T and Sderholm KJ. Some effects of water on dentin bonding. J.Dent Mater 1995; 11: 132-6.

43. Paul SJ, Leach M, Rueggeberg FA, and Pashley DH. Effect of water content on the physical properties of model dentine primer and bonding resins. J. Dentistry 1999; 27: 209-14.

44. Wakabayashi Y, Kondou Y, and Suzuki K. Effect of dissolution of collagen in adhesion to dentin. J. Int Prosthod 1994;7: 302-6.

45. Youngson CC, Jones JCG, Fox K, Smith IS, Wood DJ, and Gale M. A fluid filtration and clearing technique to assess microleakage associated with three dentine bonding systems. J. Dentistry 1999; 27: 223-33.

46. Ito S, Hashimoto M, and Wadgaonkar B. Effects of resin hydrophilicity on water sorption and changes in modulus of elasticity. J. Biomaterials 2005; 26: 6449-59.

47. Bacelar S, Ranata, Abuna, and Vitti F Adhesion evaluation of dentin sealing ,macropermeability, and bond strength of current HEMA free adhesive to dentin J. Adhesive Dentistry 2017;4;59-65

48. Pashley DH, Ciucchi B, Sano H, and Horner JA. Permeability of dentin to adhesive agents. Quintessence International 1993; 24: 618-31

49. Burrow MF, Inokoshi S, and Tagami J. Water sorption of several bonding resins. J. American Dentistry 1999; 12: 295-8.

50. Sano H, Yoshikawa T, Pereira P, and Pashley D. Long-term durability of dentin bonds made with a self-etching primer, in vivo. J. Dental Research 1999; 8: $906-11$.

51. Mortier E, Gerdolle DA, Jacquot B, and Panighi MM. Importance of water sorption and solubility studies for couple bonding agent/resin-based filling material. J. Operative Dentistry 2004; 29:87-94

52. Bachelar-S,GianniniK, and Bedran-R Bond strength and permeability of HEMA-free adhesives to biomodified dentin. Dent Mater -5641(14)X0011-4”2014 ;30:25-33.

53. Alireza S, Amir G, Yasushi S, and Junji. Effect of storage time and temperature on the properties of two self-etching systems. J dent 2007;56:218-225

54. Malacarne J, Andrade E, Wang L, Goes MF, and Martins AL. Permeability of Dental Adhesives - A SEM Assessment. Eur J Dent 2010; 4: 429-439.

55. Bacelar S,Ranata, Abuna, and Vitti F Adhesion evaluation of dentin sealing ,macropermeability , and bond strength of current HEMA free adhesive to dentin J. Adhesive Dentistry 2017;4;59-65

56. Ayseg $1 \mathrm{C}$, Seval, lmez, and Nilu. HEMA diffusion from dentin bonding agents in young and old primary molars in vitro Dent Mater $2006 ; 8 ; 40-48$ 